\title{
GRANULAR YBaCUO FILMS PREPARED BY METALORGANIC CHEMICAL AEROSOL DEPOSITION TECHNOLOGY
}

Q. TANG, H. ALBERS, A. DRIESSEN, L. T. H. HILDERINK, P. V. LAMBECK and TH. J. A. POPMA

Faculties of Applied Physics and Electical Engineering

University of Twente, P.O. Box 217, 7500 AE Enschede The Netherlands

ABSTRACT

Fine-grain thin superconducting films can be prepared by metalorganic Chemical Aerosol Deposition Technology (CADT). In this paper, we present the preparation and properties of $\mathrm{YBa}_{2} \mathrm{Cu}_{3} \mathrm{O}_{7-\mathrm{x}}$ films on the different substrates, Si and $\mathrm{SrTiO}_{3}(100)$. It is shown that the zero-resistance temperature $\left(\mathrm{T}_{\mathrm{c}, 0}\right)$ of the films on $\mathrm{SrTiO}_{3}$ substrates is about $90 \mathrm{~K}$, and the critical current density $\left(J_{c}\right)$ at $77 \mathrm{~K}$ is above $10^{4} \mathrm{~A} / \mathrm{cm}^{2}$. In addition, these films exhibit significant grain-boundary weak link behaviour, which is very promising for applications in electronic devices.

KEYWORDS

Aerosol depostion; metalorganic; ceramic superconducting thin film; weak link; annealing.

INTRODUCTION

Chemical Aerosol Deposition Technology (CADT) (Lambeck et al., 1986) has some advantages for preparing high $T_{c}$ ceramic films. It is a simple non-vacuum method and can be used to produce large-area homogeneous (in composition and thickness) films having a high quality. During the last twenty years CADT was developed to produce thin films of metals, metal oxides and sulphides (Popma and Kamminga, 1977, Blandenet et al., 1981). After the discovery of a new class of high $\mathrm{T}_{c}$ superconductors it has been successfully used to prepare high $\mathrm{T}_{c}$ superconducting films using nitrate (Gupta et al., 1988, Golden et al., 1990) or metalorganic (Tang et al., 1990) precursors. In contrast to the vacuum-deposition techniques, the caDT is able to obtain a finely granular morphology with stoichiometric grains. In fact, aerosol process (spray pyrolysis) has aroused great interest in the fabrication of fine single-crystal powders, because by this way the size of the powders is uniform and can be controlled in the range from submicron to a few micron order (Kodas et al., 1989, Tohge et al., 1988, Setaka et al., 1988). With respect to the film studies, our interest lies in some unusual properties which are due to the weakly coupled fine grains. Recently, based on the results of our investigation, a network of grain-boundary weak links has been reported (Driessen et al., 1990). This property is very promising for applications in electronic devices, such as SQUIDs and ultra-fast light detectors (Tang et al., 1990), etc.

In previous studies, we reported that the $\mathrm{YBa}_{2} \mathrm{Cu}_{3} \mathrm{O}_{7-x}$ films were prepared by metalorganic precursors $\mathrm{Y}(\mathrm{TMHD})_{3}, \mathrm{Ba}(\mathrm{TMHD})_{2}$ and $\mathrm{Cu}(\mathrm{TMHD})_{2}$, where TMHD was the chelating ligand 2,2,6,6tetramethyl-3,5-heptanedione. The results showed that a single phase of yBacuo orthorhombic structure could be obtained. We chose these metalorganic salts because they were highly volatile and could be dissolved in several organic solvents (Driessen et al., 1989). In this paper, we report on the deposition characteristics of CADT with the same precursors. The superconducting properties of $\mathrm{YBa}_{2} \mathrm{Cu}_{3} \mathrm{O}_{7-x}$ films on SrTiO substrates are described and emphasis is laid on the formation of fine grains during the annealing process.

\section{EXPERIMENTAL PROCEDURE}

Fig.1 shows the schematic diagram of a non-vacuum CADT apparatus which is placed in a dustfree cabinet. A solution of a mixture of $\beta$-diketonates of $Y$, $B a$ and $C u$ in the organic solvent n-butylacetate $\left(\mathrm{C}_{6} \mathrm{H}_{12} \mathrm{O}_{5}\right)$ was nebulized by an ultrasonic nebulizer (3 MHz). The aerosol droplets in the range of 1-3 $\mu$ mere formed. A carrier gas, consisting of $208 \mathrm{O}_{2}$ in $\mathrm{N}_{2}$ at a flow rate of $3 \mathrm{l} / \mathrm{min}$, was used to spray the aerosol onto a heated substrate at $450^{\circ} \mathrm{C}$. The concentrations of the $\mathrm{Y}-, \mathrm{Ba}-$ and Cu-compounds in the solution were $3.1,32$ and 
$7.0 \mathrm{mM}$, respectively. This ratio differed from the stoichiometric ratio because of different volatility of the compounds. It turned out that the metalorganics and the solvent had to be free of water, even of crystalwater. Incorporation of water or oH-groups in the solution drastically changed the solubility and volatility. The concentration of aerosol droplets in the carrier gas was about $0.4 \mathrm{ml} / 1$. The deposition rate was $7 \mathrm{~nm} / \mathrm{min}$. Two kinds of substrates, 2" Si wafer and $\mathrm{SrTiO}_{3}(100)$ single crystal, were used in this work. No specific pre-treatment was done on the $\mathrm{SrTiO}_{3}$ substrates, but a $250 \mathrm{~nm} \mathrm{ZrO}_{2}$ buffer layer was evaporated on the $\mathrm{Si}$ substrates in order to avoid $S i$ diffusion into the films during annealing. Although the quality of the film on both substrates was quite different with respect to $T_{c}$ and $J_{c}$, the film morphology and grain size were similar. Therefore, in the present work we restrict ourselves to the studies of the grain formation on $\mathrm{Si}$ substrates.

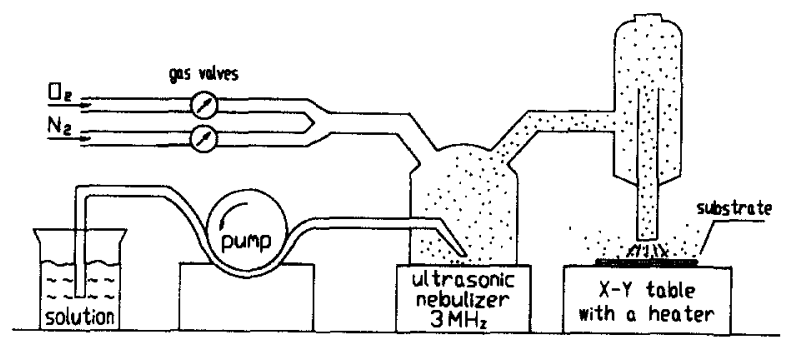

The preparation of superconducting layers by this way was a two-step process. After deposition, an annealing treatment in oxygen was required to form the superconducting phase. In our case the following heat treatments were used: (1) warming up from $250^{\circ} \mathrm{C}$ to the maximum annealing temperature at a rate of $20^{\circ} \mathrm{C} / \mathrm{min}$ under a flow of $\mathrm{N}_{2}$ gas. With this relatively slow rate, cracks in the film could be avoided. (2) Retaining the annealing temperature for 20 minutes, still under the flow of $\mathrm{N}_{2}$ gas. (3) Finally cooling down to $300^{\circ} \mathrm{C}$ slowly at a rate of $0.5^{\circ} \mathrm{C} / \mathrm{min}$ under a flow of $\mathrm{O}_{2}$ gas.

A continuous-flow cryostat with a temperature controller was used to measure the electrical properties. Resistivity versus temperature (R-T) curves were measured by the conventional four-probe technique. The critical current densities $\left(J_{c}\right)$ and current-voltage (I-V) characteristics were obtained with a microbridge, of typical dimensions $10 \times 10 \mu \mathrm{m}^{2}$, which was made by ion-beam milling. The film morphology and the grain size were observed by a dual-stage scanning electron microscope (SEM).

\section{RESULTS AND DISCUSSION}

Film morphology.

As-sprayed films are dense and show small surface roughness. The Y, Ba and Cu elements in the film are present partially as carbonates which are partly in amorphous state. The
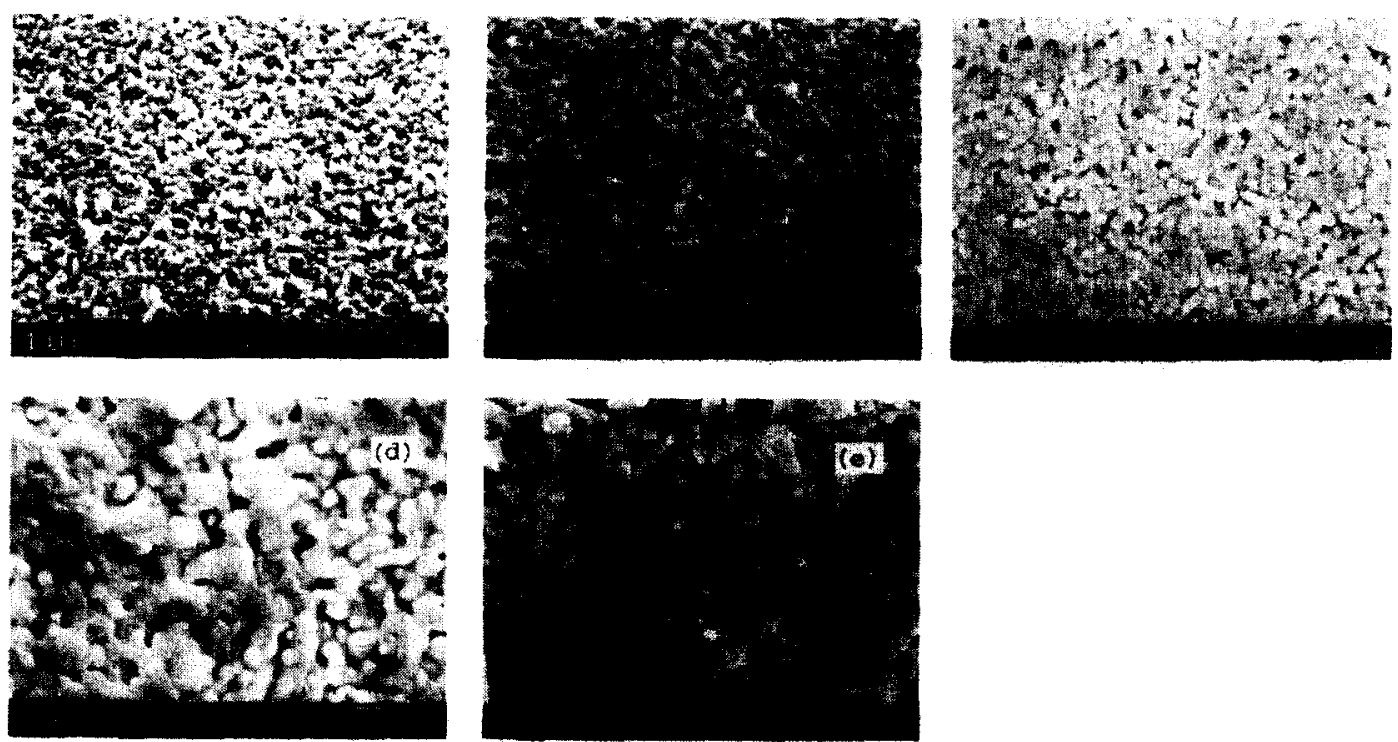

Fig. 2. SEM photographs of the film surface for different annealing temperatures on $\mathrm{Si}$ substrates, (a) $650^{\circ} \mathrm{C}$, (b) $700^{\circ} \mathrm{C}$, (c) $750^{\circ} \mathrm{C}$, (d) $800^{\circ} \mathrm{C}$ and (e) $900^{\circ} \mathrm{C}$ 
formation of the fine superconducting grains due to annealing are shown in the SEM photographs in Figs.2(a)-(e). The R-T curves as a function of annealing temperature for the same samples are given in Fig.3. Up to $650^{\circ} \mathrm{C}$ annealing no obvious changes of film morphology are observed; the corresponding $R-T$ curve presents strongly semiconducting behaviour. Above $700^{\circ} \mathrm{C}$ annealing the layer starts to recrystalize and the compounds convert to the superconducting phase. The average grain size increases singificantly with the increase of annealing temperature. The dimensions of grain size after annealing at 700,750 and $800^{\circ} \mathrm{C}$ are $50-100$, 100-200 and 250-300 nm, respectively. By annealing at $750^{\circ} \mathrm{C}$ the resistance does not show obvious increase as the temperature decreases during measurement. And above this annealing temperature the R-T curve exhibits metallic behaviour. In our case the optimal annealing temperature is about $800^{\circ} \mathrm{C}$ on both $\mathrm{Si}$ and $\mathrm{SrTiO}_{3}$ substrates. The R-T curve after annealing at $800^{\circ} \mathrm{C}$ is also shown in Fig.3. When a further higher annealing temperature is applied, for example $900^{\circ} \mathrm{C}$, the crystalline phase after annealing is a nonsuperconducting phase. The resistance of the film then is higher than 20 $M \Omega$ at room temperature. Comparing the morphology in Figs.2(d) and (e), some differences can be seen. In Fig.2(e), (1) a lot of large grains with clear boundaries are formed; (2) some small spherical grains are present on the top of the film surface; (3) the film looks more porous. X-ray diffraction patterns show that no diffraction peaks of the superconducting phase can be found. A reason for our optimal annealing temperature is that probably this temperature is just high enough to allow the formation of the orthorhombic structure with stoichiometric oxygen concentration, and low enough to avoid other phase transitions or excessive diffusion from the substrate to the films. Because of the large variety of processing parameters contributing to the formation of these fine grains, the exact control of supercon ducting grain size has not been realized yet.

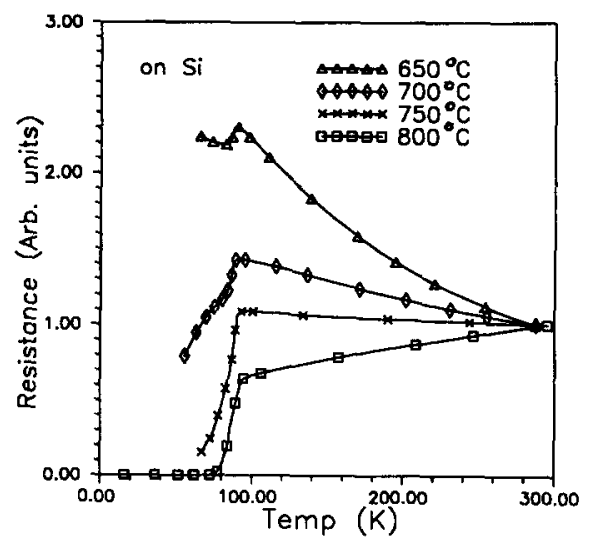

Fig. 3. R-T curves for different annealing temperatures on $\mathrm{Si}$ substrates.

\section{Superconductivity.}

In Fig.4 we display the R-T curve of a high quality film with thickness $250 \mathrm{~nm}$ on a SrTiO 3 substrate. As can be seen, the $T_{c, 0}$ is $90 \mathrm{~K}$ and the transition width is about $3 \mathrm{~K}$. The

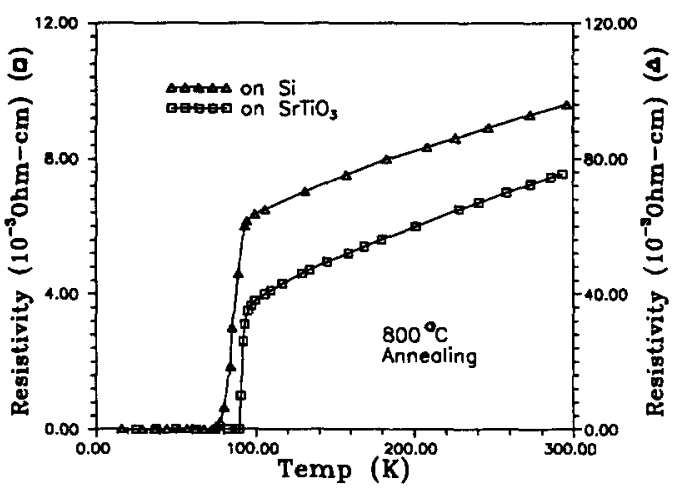

Fig. 4. R-T curves on different substrates. $10 \mu \mathrm{A}$ currents are used for the measurements.

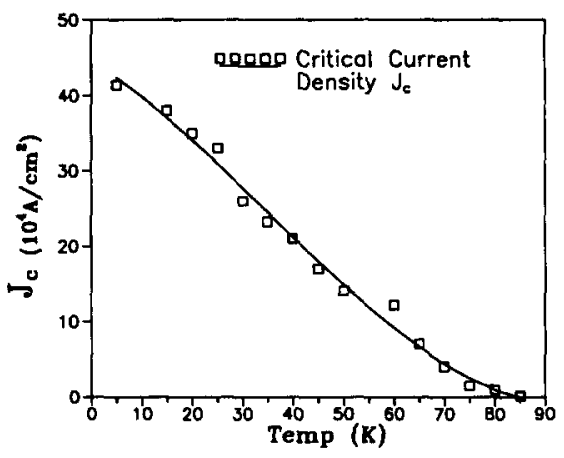

Fig. 5. Critical current density $J_{c}$ as a function of temperature on a $\mathrm{SrTiO}_{3}$ substrate.

film with thickness $700 \mathrm{~nm}$ on a $\mathrm{Si}$ substrate however exhibits a low $\mathrm{T}_{\mathrm{C}}$ and a broad transition. X-ray diffraction analysis indicates that the best films on both substrates possess an orthorhombic structure with a perpendicular c-axis orientation and only 001 diffraction peaks $(1=2,3,4,5,6$ and 7$)$ can be observed. When the composition deviates from the stoichiometric $1: 2: 3$ ( $\mathrm{Y}: \mathrm{Ba}: \mathrm{Cu}$ ) compound, a second phase is also present in our films and a lower $\mathrm{T}_{\mathrm{C}}$ (less than $50 \mathrm{k}$ ) can be found (Tang et al., 1990). The temperature dependence of the critical current density $\mathrm{J}_{c}$ on a $\mathrm{SrTiO}_{3}$ substrate is show in Fig.5. The curve measured on a $10 \times 10 \mathrm{\mu m}^{2}$ microbridge indicates that the $\mathrm{J}_{\mathrm{c}}$ at $77 \mathrm{~K}$ is above $10^{4} \mathrm{~A} / \mathrm{cm}^{2}$ and approximate $4 \times 10^{5} \mathrm{~A} / \mathrm{cm}^{2}$ at $4 \mathrm{~K}$.

There are two points to be noted. First, the films prepared by CADT have relatively high 
resistivity at the temperature just above the onset transition. The values of resistivity are about $4 \times 10^{-3} \Omega \cdot \mathrm{cm}$ on $\mathrm{SrTiO}_{3}$ substrates and are about $6 \times 10^{-2} \Omega \cdot \mathrm{cm}$ on $\mathrm{Si}$ substrates. The maximum values of ratio $R_{300} / R_{100}$ on $\mathrm{SrTiO}_{3}$ and $\mathrm{Si}$ substrates are about 1.98 and 1.52 , respectively, where $R_{300}$ and $R_{100}$ are resistances of the $f i l m$ at temperatures of 300 and $100 \mathrm{~K}$. Second, with respect to the extrapolation of the R-T curves to the zero temperature, the resistivity does not go to zero. These two points can be explained by assuming that the total resistance is caused by the contribution of the superconducting grains and also of the grain boundaries. The boundaries act as barriers of normal metal separating the superconducting grains. Therefore intrinsic weak links are present in these fine grain films. Weak link behaviour in an I-V curve has been observed on a $\mathrm{SrTiO}_{3}$ substrate at $79 \mathrm{~K}$. An oscilloscope photograph is shown in Fig.6. The vertical scale is 0.5 $\mathrm{v} / \mathrm{div}$ and the horizontal one is $3.5 \mathrm{~mA} / \mathrm{div}$. This abrupt voltage jump in the $I-V$ curve provides strong evidence of nonequilibrium superconductivity.

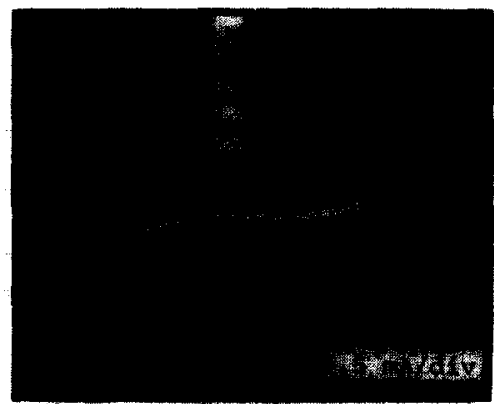

Fig. 6. Weak link behaviour in an I-V curve at $79 \mathrm{~K}$. Bias current is supplied by a triangle wave of $20 \mathrm{~Hz}$ frequency.

In conclusion, fine-grain $\mathrm{YBa}_{2} \mathrm{Cu}_{3} \mathrm{O}_{7-x}$ superconducting films with a perpendicular c-axis orientation have been obtained by CADT. The film quality is strongly dependent on the different substrates and annealing processes. In our case the optimal annealing temperature on both $\mathrm{Si}$ and $\mathrm{SrTiO}_{3}$ substrates is about $800^{\circ} \mathrm{C}$. These films exhibit significant weak link behaviour. Based on that the films can be applied to electronic devices.

\section{REFERENCES}

Blandenet,G., M.Court and Y.Lagarde (1981). Thin layers deposited by the pyrosol process. Thin Solid Films, 77, 81-90.

Driessen,A., Q.Tang, L.Hilderink and Th.J.A.Popma (1989). Production of Y-Ba-Cu-O superconducting thin films by an aerosol chemical vapor deposition process. In: Proc. MRS Fall Meeting, Boston, Symp.M.

Driessen, A., Q.Tang, P.Hoekstra and Th.J.A.Popma (1990). Dynamically-enhanced supercurrents in granular superconducting $\mathrm{Y}-\mathrm{Ba}-\mathrm{Cu}-\mathrm{O}$ thin films. to be published.

Golden, S.J., H.Isotalo, M.Lanham, J.Mayer, F.F.Lange and M.Ruhle (1990). Characterization of spray-pyrolized superconducting YBaCuo thin films on single-crystal Mgo by transmission electron microscopy. J. Mater. Res., 5, 1605-1611.

Gupta,A., G.Koren, E.A.Giess, N.R.Moore, E.J.M.O'Sullivan and E.I.Cooper (1988). $\mathrm{Y}_{1} \mathrm{Ba}_{2} \mathrm{Cu}_{3} \mathrm{O}_{7-x}$ thin films grown by a simple spray deposition technique. Appl. Phys. Lett., $52,163-165$.

Kodas,T.T., E.M.Engler and V.Y.Lee (1989). Generation of thick $\mathrm{Ba}_{2} \mathrm{YCu}_{3} \mathrm{O}_{7}$ films by aerosol deposition. Appl. Phys. Lett., 54, $1923-1925$.

Kodas,T., A.Datye, V.Lee and E.Engler (1989). Single-crystal $\mathrm{Y}_{1} \mathrm{Ba}_{2} \mathrm{Cu}_{3} \mathrm{O}_{7}$ particle formation by aerosol decomposition. J. Appl. Phys., 65, 2149-2151.

Lambeck,P.V., L.Hilderink and Th.J.A. Popma $(\overline{1986})$. Thin-layer formation by chemical aerosol deposition. In: Proc. 2nd Int. Aerosol Conf., Berlin, pp. 964-967.

Popma,Th.J.A., M.Kamminga (1977). A method of producing iron oxide photomasks. Us Pat. 4199621 .

Setaka,R., W.Komatsu, T.Shibata and M.Nakajima (1988). Preparation of a single crystalline powder of superconducting $\mathrm{YBa}_{2} \mathrm{Cu}_{3} \mathrm{O}_{7-x}$ by the gas phase solidification method. Jpn. J. Appl. Phys., 27, L2100-L2102.

Tang,Q., A.Driessen, L.T.Hilderink and Th.J.A.Popma (1990). YBaCuo thin films prepared by organometallic aerosol deposition. In: Physics and Material Science of High Temperature Superconductors (R.Kossowsky et al., eds.), NATO ASI Series E181, Kluwer, pp. 401-408.

Tang,Q., A.Driessen, P.Hoekstra, L.T.Hilderink, A.Van Silfhout and Th.J.A.Popma (1990). Optical response of highly granular YBaCuO films prepared by non-vacuum aerosol deposition. In: Proc. E-MRS (May 29 - June 1), Strasbourg.

Tohge,N., M.Tatsumisago, T.Minami, K.Okuyama, M.Dachi and Y.Kousaka (1988). Direct preparation of uniformly-distributed $\mathrm{YBa}_{2} \mathrm{Cu}_{3} \mathrm{O}_{7-x}$ powders by spray pyrolysis. Jpn. J. Appl. Phys., 27, L1086-I1088. 